\title{
Solution Properties of Mono- and Di-hexadecyl Cationic Mixed Surfactant Systems: Specific Coexistence Effect Among Various Aggregates
}

\author{
Sae Ogata, Yoko Sakurai, Takeshi Takano, Akihiro Yoshino, Keijiro Taga, \\ Yasushi Yamamoto, and Zameer Shervani
}

\section{ABSTRACT}

We have synthesized the surfactant cationic dihexadecyl dimethyl ammonium bromide [16-16]. The aggregates of [16-16] and hexadecyl trimethyl ammonium bromide (C16TAB) were prepared in aqueous solution in different mixing ratio $(x[16-16])$ of [16-16]. The effect of mixing ratio $(x[16-16])$ and experimental temperature on the aggregates formation were studied using a number of physicochemical methods. With an increase in $x$ [16-16], the structure of aggregates changed from spherical micelles to vesicles. In the range of specific ratio $(0.2 \leq x[16-16]$ $\leq 0.4)$ and temperature $\left(35\right.$ and $45^{\circ} \mathrm{C}$ ), worm-like micelles existed. We have demonstrated that $x[16-16]$ and temperature played an important role in deciding the type of aggregate formed in solution.

Keywords: Cationic Dihexadecyl Dimethyl Ammonium Bromide; Hexadecyl Trimethyl Ammonium Bromide; Spherical Micelle; Vesicle; Worm-like Micelle; Aqueous Aggregates; Mixing Ratio; Coexistence Effect.

Published Online: January 26, 2022

ISSN: $2684-4478$

DOI: $10.24018 /$ ejchem.2022.3.1.75

\section{Sae Ogata}

Department of Life Science and Applied Chemistry, Graduate School of Engineering, Nagoya Institute of Technology, Nagoya, Japan.

Yoko Sakurai

Department of Life Science and Applied

Chemistry, Graduate School of

Engineering, Nagoya Institute of

Technology, Nagoya, Japan.

Takeshi Takano

Department of Life Science and Applied Chemistry, Graduate School of Engineering, Nagoya Institute of

Technology, Nagoya, Japan.

Akihiro Yoshino

Department of Life Science and Applied Chemistry, Graduate School of Engineering, Nagoya Institute of Technology, Nagoya, Japan.

Keijiro Taga

Department of Life Science and Applied

Chemistry, Graduate School of

Engineering, Nagoya Institute of

Technology, Nagoya, Japan.

Yasushi Yamamoto*

Department of Life Science and Applied

Chemistry, Graduate School of

Engineering, Nagoya Institute of

Technology, Nagoya, Japan.

(e-mail: yamamoto.yasushi@nitech.ac.jp)

Zameer Shervani*

Food \& Energy Security Research \&

Product Centre, Sendai, Japan.

(e-mail: shervani.nanotek@gmail.com)

*Corresponding Author

\section{INTRODUCTION}

Surfactants are amphiphilic compounds which have both hydrophobic and hydrophilic groups in one molecule. Surfactants have the characteristics of adsorption and self-assembly. The properties of the surfactants changed dramatically depending on the class and structure of hydrophobic and hydrophilic groups. The type of surfactant, concentration, temperature of the surfactant solution and the presence of additives play important roles in forming certain aggregate structure. Because of the surface active properties, the surfactants have applications in washing and cleaning, dispersion and emulsion preparation, solubilization, wetting, foaming, and imparting the flexibility to the surfaces where the surfactants control the interfacial phenomena. Due to the above applications and phenomena, the surfactants are used vigorously in cosmetic, pharmaceutical, food, and chemical industries [1]. A surfactant in solution changes its phase from monodisperse to various aggregates such as spherical 
micelle (SM), rod-like or worm-like micelles (RM, WM), vesicles (VE), hexagonal and lamella states (HS, LS) with increasing the concentration. The concentration at which the micellar aggregates begin to form is called the critical micelle concentration (CMC). The number of molecules forming aggregates or association (aggregation number), the structure, and internal hydrophobic environment are significantly different between SM and higher-order aggregates (HOA: RM, WM, VE, HS, LS). HOA are used in medical application for drug delivery system (DDS) and in industry as reaction medium solvents including microcrystal preparation solvents [1], [2]. Israelachvili [3] proposed the critical packing parameter (CPP) of surfactants that determines the structure of aggregates in solution.

The formula is defined as:

$$
\mathrm{CPP}=V /(l \times a)
$$

where, $V$ is the volume of hydrophobic group (alkyl chain) of surfactant molecule, $l$ is the length of hydrophobic group (alkyl chain), and $a$ is the effective cross-sectional area of hydrophilic head group. The type of structure of the aggregates formed by the surfactant molecule can be correlated by the numbers using the following relationships,

$$
\begin{gathered}
C P P=<1 / 3 \text { for Spherical Micelles; } \\
1 / 3<C P P<1 / 2 \text { for Reverse Micelles and Wormlike Micelles; } \\
1 / 2<C P P<1 \text { for Vesicles, Hexagonal States, and Laminar States }
\end{gathered}
$$

The transition between SMs and VEs in a surfactant solution is of great interest due to its potential applications in various fields such as molecular templates, drug and gene deliveries. The behavior of surfactant aggregates is controlled by electrostatic forces, van der Waals forces, and the hydrophobic interactions. The above interactions can be understood well with the help of SMs to VEs transition. Many researchers have investigated SMs-VEs transition systematically in detail [4], [5]. It has been reported that the important factors for determining the type and size of the aggregates are the concentration and the mixing ratio of the surfactants [6], [7]. Surfactant system also changes their structures in response to temperature, light, $\mathrm{pH}$, and carbon dioxide content. Since the temperature is easiest to control among all the parameters, there is great interest in investigating the behavior of the aggregates versus temperature. It has been reported that the diseased tissues and organs often exhibit abnormal temperature [8], and cancer cells act at higher temperature than normal cells [9]. Thus, the temperature dependent surfactants' behavior is not only important for industries but also in biomedical fields. In this study, we have investigated the effect of the surfactant mixing ratio and temperature on the behavior of aggregates in practical concentration range. The combination of two types of cationic surfactants with similar structure of hydrophilic groups and different numbers of alkyl chains (mono- and di- hexadecyl) has been tested. A number of physicochemical methods: visual observation, viscosity measurement, dynamic light scattering (DLS), and transmission electron microscopy (TEM) have been employed.

\section{RESULTS AND DISCUSSION}

\section{A. Visual Observation}

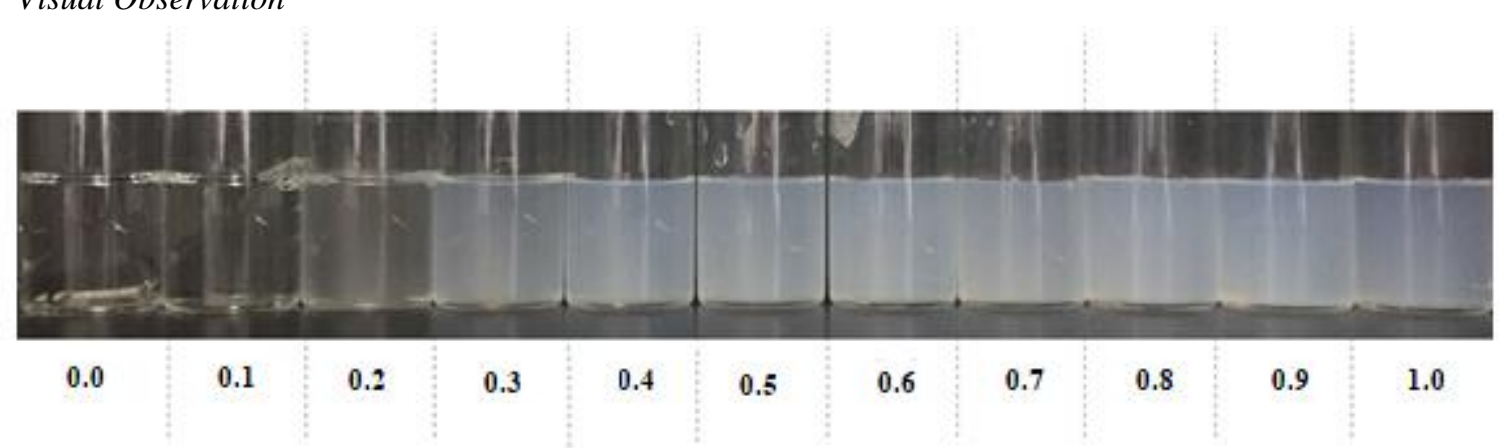

Fig. 1. Visual observation of various mixed solutions of molar ratio (x [16-16]) at $25^{\circ} \mathrm{C}$.

Fig. 1 shows the visual observation of various mixed solutions of $x_{[16-16]}$ at $25^{\circ} \mathrm{C}$. At $x_{[16-16]}=0.0$ $(\mathrm{C} 16 \mathrm{TAB})$ and 0.1 , the colors of the solutions were transparent. At $x_{[16-16]} \geq 0.2$, on the other hand, those colors changed to bluish with an increase in $x_{[16-16]}$. These images indicate that multiple aggregates coexist in each mixed solution and change their structures with an increase in $\mathrm{x}_{\text {[16-16] }}$. 


\section{B. Viscosity Measurements}
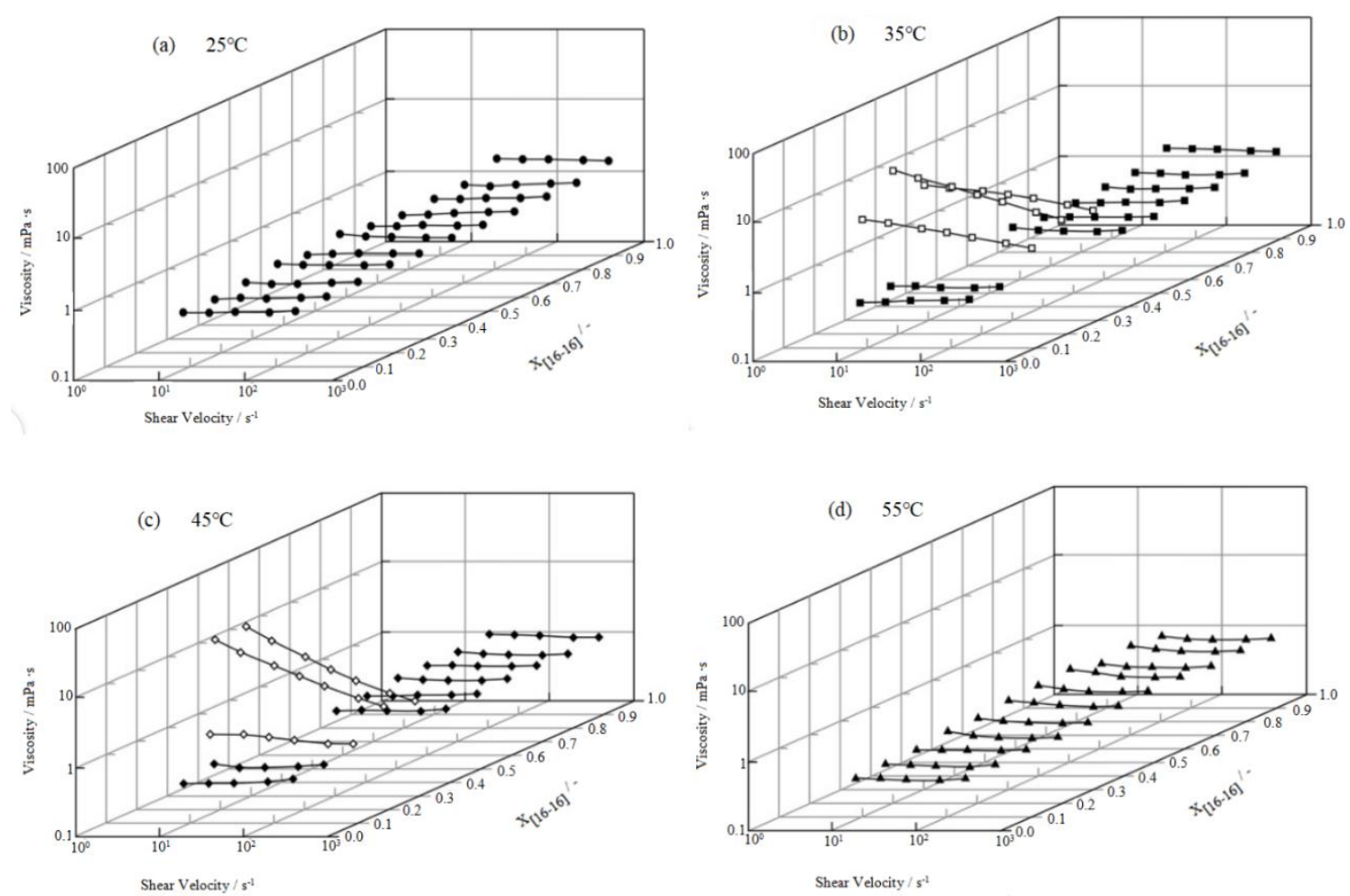

Fig. 2. Mole ratio dependence of viscosity on various C16TAB-[16-16] mixed solutions. Horizontal axis: shear velocity (s ${ }^{-1}$ ), vertical axis: viscosity (mPa•s), depth axis: $\mathrm{x}[16-16]$. (a): $25^{\circ} \mathrm{C},(\mathrm{b}) 35^{\circ} \mathrm{C},(\mathrm{c}): 45^{\circ} \mathrm{C},(\mathrm{d}): 55^{\circ} \mathrm{C}$.

Fig. 2a-d shows typical mole ratio dependence of viscosity on various C16TAB-[16-16] mixed solutions at various measured temperatures. Horizontal axis is shear velocity $\left(\mathrm{s}^{-1}\right)$, vertical axis represents viscosity (mPa.s), and depth axis shows $x_{[16-16]}$. Fig. 2a, 2b, 2c, and 2d, are the measurements conducted at $25^{\circ} \mathrm{C}, 35^{\circ} \mathrm{C}, 45^{\circ} \mathrm{C}$, and $55^{\circ} \mathrm{C}$, respectively. At $25^{\circ} \mathrm{C}$ and $55^{\circ} \mathrm{C}$ (Fig. $2 \mathrm{a}$ and $2 \mathrm{~d}$ ), the viscosity values on each $x_{[16-16]}$ were constant on the measured shear velocity range. Those values also increased slightly linearly from $0.91 \mathrm{mPa} \cdot \mathrm{s}\left(x_{[16-16]}=0.0(\mathrm{C} 16 \mathrm{TAB})\right)$ to $1.46 \mathrm{mPa} \cdot \mathrm{s}\left(x_{[16-16]}=1.0([16-16])\right)$ at $25{ }^{\circ} \mathrm{C}$ and from $0.57 \mathrm{mPa} \cdot \mathrm{s}\left(x_{[16-16]}=0.0\right)$ to $0.65 \mathrm{mPa} \cdot \mathrm{s}\left(x_{[16-16]}=1.0\right)$ at $55^{\circ} \mathrm{C}$, and were similar to that of water $\left(0.89 \mathrm{mPa} \cdot \mathrm{s}\right.$ at $\left.25^{\circ} \mathrm{C}\right)$. So, this indicated that these mixed solutions at $25^{\circ} \mathrm{C}$ and $55^{\circ} \mathrm{C}$ are Newtonian fluid. From the rheological properties of the surfactant solution, it is known that the solution forming SM and VE shows Newtonian fluid, while that of WM shows non-Newtonian fluid (shear thinning behavior) [10], [11], [12]. Therefore, the constant viscosity of C16TAB-[16-16] mixed solutions at 25 and $55^{\circ} \mathrm{C}$ indicates the formation of SMs and/or VEs in the solution. At 35 and $45^{\circ} \mathrm{C}$ (Fig. $2 \mathrm{~b}$ and c), the tendency of the viscosity of $x_{[16-16]} \leq 0.1$ and $\geq 0.5$ was the same as those at 25 and $55^{\circ} \mathrm{C}$. The viscosities of these solutions did not change the values and were constant on the measured shear velocity range. At $35^{\circ} \mathrm{C}$, the value of $x_{[16-16]} \leq 0.1$ was $0.74\left(x_{[16-16]}=0.0(\mathrm{C} 16 \mathrm{TAB})\right)$ and $0.78\left(x_{[16-16]}=0.1\right) \mathrm{mPa} \cdot \mathrm{s}$, respectively, and those values at $x_{[16-16]} \geq 0.5$ increased slightly linearly from $0.83 \mathrm{mPa} \cdot \mathrm{s}\left(x_{[16-16]}=0.5\right)$ to $1.24 \mathrm{mPa} \cdot \mathrm{s}\left(x_{[16-16]}\right.$ $=1.0([16-16]))$. At $45^{\circ} \mathrm{C}$, the value of $x_{[16-16]} \leq 0.1$ was $0.62\left(x_{[16-16]}=0.0\right)$ and $0.64\left(x_{[16-16]}=0.1\right) \mathrm{mPa} \cdot \mathrm{s}$, respectively, and those values at $x_{[16-16]} \geq 0.5$ increased slightly linearly from $0.71 \mathrm{mPa} \cdot \mathrm{s}\left(x_{[16-16]}=0.5\right)$ to $0.86 \mathrm{mPa} \cdot \mathrm{s}\left(x_{[16-16]}=1.0\right)$. Since these values were similar to that of water, this indicated that these mixed solutions are Newtonian fluid, similar to those at 25 and $55^{\circ} \mathrm{C}$. However, at $0.2 \leq x_{[16-16]} \leq 0.4$ in 35 and $45^{\circ} \mathrm{C}$ (Fig. $2 \mathrm{~b}$ and c), the viscosity showed different behavior from those at of $x_{[16-16]} \leq 0.1$ and $\geq 0.5$; the viscosity decreased with an increase in shear velocity. On $x_{[16-16]}=0.3$ at $45^{\circ} \mathrm{C}$ (Fig. 2b), the viscosity value decreased from $17.9 \mathrm{mPa} \cdot \mathrm{s}$ (max.) at $1 \mathrm{rpm}$ to $2.0 \mathrm{mPa} \cdot \mathrm{s}$ (min.) at $100 \mathrm{rpm}$. This tendency is a typical non-Newtonian fluid (shear thinning behavior) and indicates the formation of WMs in the solution [10], [11], [12]. Viscosity values measured (average of constant values) were described in Table IA\&B, except for $0.2 \leq x_{[16-16]} \leq 0.4$ at 35 and $45^{\circ} \mathrm{C}$.

TABLE IA: Viscosity Values (AVERAGE) ON VARIOUs Mole Ratio (X[16-16]) ObTained FROM Fig. 2, EXCEPT FOR $0.2 \leq \mathrm{X}[16-16] \leq 0.4$ AT 35 AND $45^{\circ} \mathrm{C}$

\begin{tabular}{|c|c|c|c|c|c|c|c|c|c|c|c|c|}
\hline \multirow[b]{2}{*}{ Temp. $\left({ }^{\circ} \mathrm{C}\right)$} & \multicolumn{11}{|c|}{$X[16-16]$} & \multirow{2}{*}{ Water } \\
\hline & 0.0 & 0.1 & 0.2 & 0.3 & 0.4 & 0.5 & 0.6 & 0.7 & 0.8 & 0.9 & 1.0 & \\
\hline 25 & 0.91 & 0.94 & 0.97 & 1.09 & 1.03 & 1.11 & 1.02 & 0.96 & 1.02 & 1.02 & 1.46 & 0.89 \\
\hline
\end{tabular}


TABLE IB: Viscosity Values (AVERAGE) ON VARIOUS Mole Ratio (x[16-16]) OBtained FROM Fig. 2, EXCEPT FOR $0.2 \leq \mathrm{X}[16-16] \leq 0.4$ AT 35 AND $45^{\circ} \mathrm{C}$

\begin{tabular}{|c|c|c|c|c|c|c|c|c|c|c|c|c|}
\hline \multirow{2}{*}{ Temp. $\left({ }^{\circ} \mathrm{C}\right)$} & \multicolumn{11}{|c|}{$\mathrm{X}$ [16-16] } & \multirow{2}{*}{ Water } \\
\hline & 0.0 & 0.1 & 0.2 & 0.3 & 0.4 & 0.5 & 0.6 & 0.7 & 0.8 & 0.9 & 1.0 & \\
\hline 35 & 0.74 & 0.78 & - & - & - & 0.83 & 0.81 & 0.81 & 0.86 & 0.88 & 1.24 & 0.72 \\
\hline 45 & 0.62 & 0.66 & - & - & - & 0.71 & 0.71 & 0.77 & 0.80 & 0.75 & 0.86 & 0.60 \\
\hline 55 & 0.57 & 0.58 & 0.59 & 0.62 & 0.63 & 0.72 & 0.70 & 0.76 & 0.64 & 0.70 & 0.65 & 0.51 \\
\hline
\end{tabular}

\section{Dynamic Light Scattering (DLS) Measurement}
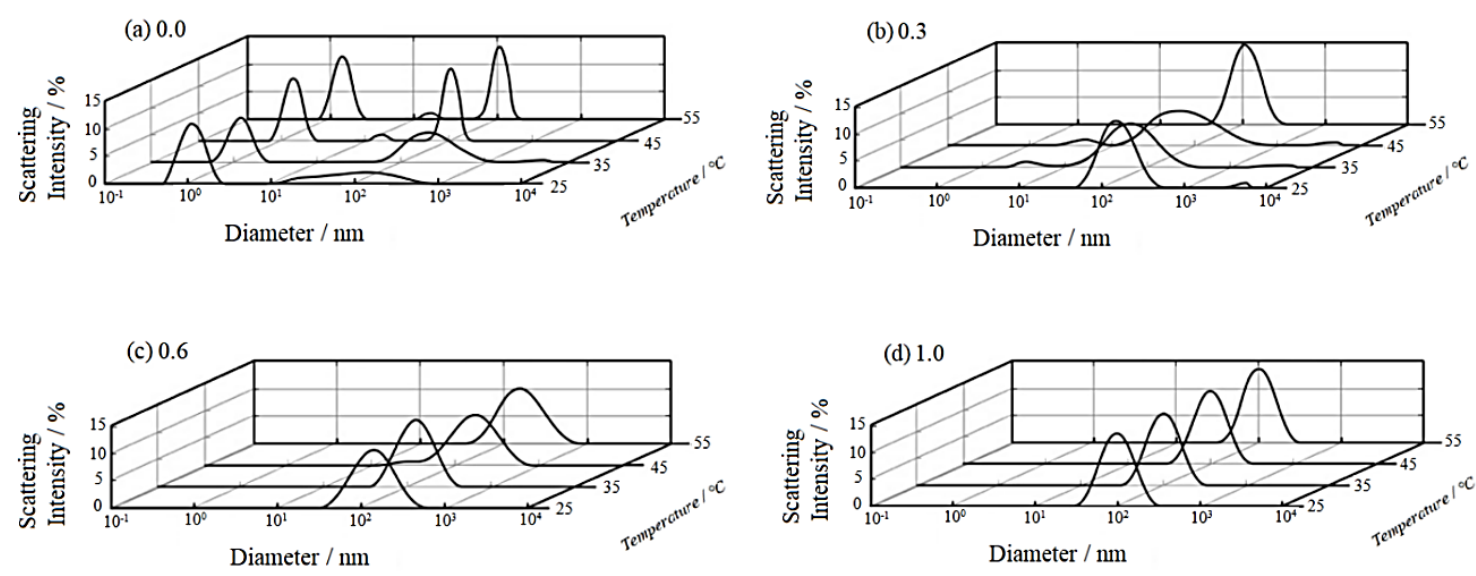

Fig. 3. Scattering intensity of DLS at $x$ [16-16]-selected C16TAB-[16-16] mixed solutions. Horizontal axis: diameter (nm), vertical axis: scattering intensity (\%), depth axis: temperature $\left({ }^{\circ} \mathrm{C}\right)$. (a): $\mathrm{x}[16-16]=0.0,(\mathrm{~b}): 0.3,(\mathrm{c}): 0.6,(\mathrm{~d}): 1.0$.

Fig. 3(a-d) shows DLS results at $\left.x_{[16-16]}\right]^{-s e l e c t e d ~ C 16 T A B-[16-16] ~ m i x e d ~ s o l u t i o n s ~}\left(x_{[16-16]}=0.0,0.3\right.$, $0.6,1.0)$ at various measured temperatures. Horizontal axis is diameter $(\mathrm{nm})$, vertical axis scattering intensity $(\%)$, and depth axis temperature $\left({ }^{\circ} \mathrm{C}\right)$. There are several analytical methods in DLS measurement [13]. In this study, we adopted standard method of scattering intensity because measured solutions may contain aggregates of various shapes. At $x_{[16-16]}=0.0$ (C16TAB solution, Fig. 3a), several peaks were observed over the wide diameter range at $1 \mathrm{~nm}$ and from several tens to hundreds $\mathrm{nm}$ at all measured temperatures. On the 16TAB solution at more than CMC, SM is formed and the size of the SM has also been reported as several $\mathrm{nm}$ in diameter at room temperature [14], [15]. In $10 \mathrm{mmol} / \mathrm{kg} \mathrm{C16TAB}$ solution, these SMs move violently in Brownian motion and have the characteristic of being easily aggregated due to an increase in approach and collision between SMs. Actually, C16TAB solution of $1.4 \mathrm{mmol} / \mathrm{kg}$ at 25 ${ }^{\circ} \mathrm{C}$ showed two exact peaks at 5 and $130 \mathrm{~nm}$ (data not shown). The peak of $5 \mathrm{~nm}$ is consistent with the theoretical value $(4.8 \mathrm{~nm})$ calculated under Tanford's assumption that the alkyl chain in the SM is almost straight [16]. With an increase in concentration of solution, on the other hand, the lower value $(5 \mathrm{~nm})$ in two peaks gradually decreased and reached $1 \mathrm{~nm}$ (data not shown). This experimental fact may be also an instrumental and/or analytical characteristic that appears on the DLS measurements of mono- and multidispersed complex solution (comparatively high concentration) composed by small particles. It follows that the peaks observed $1 \mathrm{~nm}$ and over the wide diameter range would be attributed to several monoC16TAB SMs and apparent aggregates of C16TAB SMs. In addition, it is found that C16TAB forms SM over a wide temperature range.

At $x_{[16-16]}=0.3$ (Fig. 3b), a single peak of $150 \mathrm{~nm}$ was observed at 25 and $55^{\circ} \mathrm{C}$, whereas quite a large wide peak was observed over a wide range from several to less than thousand nm was observed at 35 and $45^{\circ} \mathrm{C}$. Based on the results of bluish solution state and behavior of Newtonian fluid, the single peak at 25 and $55^{\circ} \mathrm{C}$ suggests the formation of VE in the solution. The large wide peak at 35 and $45{ }^{\circ} \mathrm{C}$, on the other hand, was specific shape different from those of all previous DLS results. Based on the results of behavior of non-Newtonian fluid (Fig. 2b and c), the large wide peak suggests the formation of WM in the solution. WMs are entangled in the solution [11], [12], [17], [18], [19] and the particle size that assumed to be spherical particles at DLS analysis [13] differs depending on the degree of their entanglement. This corresponds to the large wide peak over a wide range in diameter. From these results, it is found that structural transition between VE and WM occurs at $x_{[16-16]}=0.3$ due to the change of temperature. At $x_{[16-}$ ${ }_{16}=0.6$ (Fig. 3c), single peak of $150 \mathrm{~nm}$ was observed at all the temperatures. From the same interpretation as the above $x_{[16-16]}=0.3$ at 25 and $55^{\circ} \mathrm{C}$, the peak suggests the formation of VE in the solution and as the same size as that of the above $x_{[16-16]}=0.3$ at 25 and $55^{\circ} \mathrm{C}$. At $x_{[16-16]}=1.0$ (Fig. $3 \mathrm{~d}$ ), single peak of $100 \mathrm{~nm}$ was observed at all the temperatures. From the same interpretation as the above $x_{[16-16]}=0.3$ at 25 and $55{ }^{\circ} \mathrm{C}$, the peak suggests the formation of VE in the solution. Furthermore, it is found that the size of VE at $x_{[16-16]}=1.0$ is smaller than that at $x_{[16-16]}=0.3$ at 25 and $55^{\circ} \mathrm{C}$ and $x_{[16-16]}=$ 0.6 . 


\section{Transmission Electron Microscope (TEM) Observation}

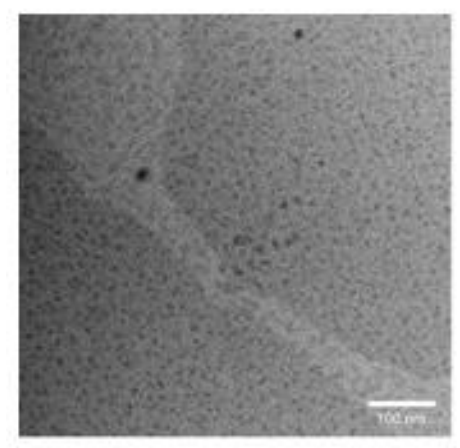

(a) $0.0,25^{\circ} \mathrm{C}$

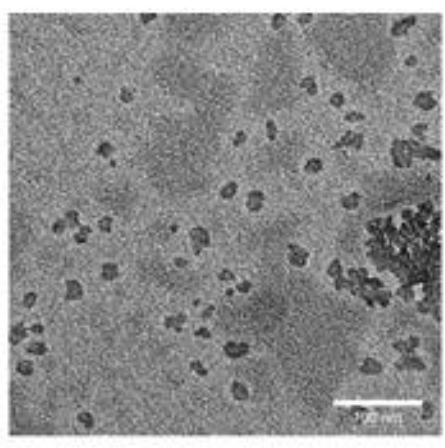

(b) $0.3,25^{\circ} \mathrm{C}$

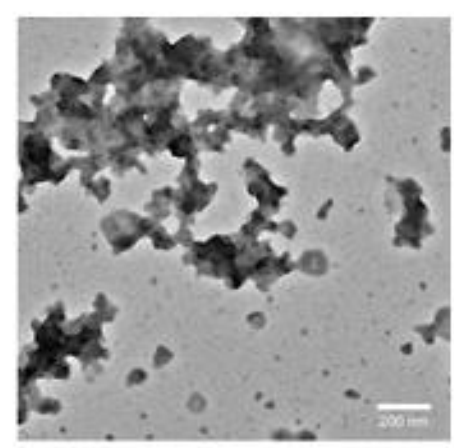

(c) $0.3,35^{\circ} \mathrm{C}$

Fig. 4. TEM image of $x$ [16-16]-selected C16TAB-[16-16] mixed solutions. (a): $x[16-16]=0.0$ at $25^{\circ} \mathrm{C},(\mathrm{b}): 0.3$ at $25{ }^{\circ} \mathrm{C},(\mathrm{c}): 0.3$ at $35^{\circ} \mathrm{C}$.

Fig. 4(a-c) shows TEM image of $\left.x_{[16-16]}\right]^{-s e l e c t e d ~ C 16 T A B-[16-16] ~ m i x e d ~ s o l u t i o n s . ~(a) ~ i s ~} x_{[16-16]}=0.0$ $(\mathrm{C} 16 \mathrm{TAB})$ at $25^{\circ} \mathrm{C}$, (b) is $x_{[16-16]}=0.3$ at $25^{\circ} \mathrm{C}$, and (c) is $x_{[16-16]}=0.3$ at $35^{\circ} \mathrm{C}$, respectively. The scale bar in each figure is $100.0 \mathrm{~nm}$ for (a) and (b), and $200.0 \mathrm{~nm}$ for (c), respectively. On the $x_{[16-16]}=0.0$ at 25 ${ }^{\circ} \mathrm{C}$ (Fig. 4a), the image showed the existence of several aggregates that those diameters were $5 \mathrm{~nm}$ per one aggregate and some of them were in a state where some aggregates gathered each other (diameter $>20$ $\mathrm{nm}$ ). The image corresponded to the result and interpretation of DLS at $x_{[16-16]}=0.0$ (Fig. 3a), consequently the formation of SM at $25^{\circ} \mathrm{C}$. On the $x_{[16-16]}=0.3$ at $25^{\circ} \mathrm{C}$ (Fig. 4b), the image showed the existence of several aggregates that those diameters were several tens $\mathrm{nm}$ per one aggregate and some of them were in a state where some aggregates gathered each other (diameter $>100 \mathrm{~nm}$ ). This image indicates the formation of $\mathrm{VE}$ at $25{ }^{\circ} \mathrm{C}$ because the size of aggregates was an order magnitude larger than that of $x_{[16-16]}=0.0$ at $25^{\circ} \mathrm{C}$ (Fig. 4a), whereas was a little different from the result of DLS (Fig. 3b) in terms of the aggregate diameter. On the $x_{[16-16]}=0.3$ at $35^{\circ} \mathrm{C}$ (Fig. 4c), the image showed a state where various aggregates gathered and connected like worm and they also entangled each other. Their sizes had wide range from several tens to hundreds $\mathrm{nm}$ in length. These images corresponded to the result of DLS at $x_{[16-16]}=0.3$ (Fig. 3b), consequently the formation of WM at $35^{\circ} \mathrm{C}$. These results also support that Zeta potential of the solution on the DLS measurement decreased significantly from $59.2 \mathrm{mV}$ at $25{ }^{\circ} \mathrm{C}$ to 24.7 $\mathrm{mV}$ at $35^{\circ} \mathrm{C}$ on the $x_{[16-16]}=0.3$, the occurrence of structural change of aggregates in the solution.

\section{E. Phase Diagram and Mechanism of Aggregate Formation}

Fig. 5 shows phase diagram of C16TAB-[16-16] mixed solutions estimated from the above results of visual observation, viscosity, DLS, and TEM. The phase diagram is roughly classified into three phases, SM, VE, and WM. We will attempt to discuss the mechanism of their aggregate formation from the viewpoint of the mixing ratio and temperature effects in relation to each other and the concept of CPP.

In Fig. 5, SM is formed in the solution at $x_{[16-16]}=0.0$ (C16TAB solution) by the SM-forming ability $(\mathrm{CPP}<1 / 3)$ of $\mathrm{C} 16 \mathrm{TAB}$ at $25^{\circ} \mathrm{C}$ [14], [15], [20], [21]. This ability is also maintained until $55^{\circ} \mathrm{C}$ from the DLS result, in other words, maintaining of CPP $<1 / 3$ condition. At $x_{[16-16]}=1.0$ ([16-16] solution), on the other hand, VE is formed in the solution by the VE-forming ability $(1 / 2<\mathrm{CPP}<1)$ of [16-16] at $25^{\circ} \mathrm{C}$. Tucker et al. [22] have reported that [16-16] forms bilamellar vesicles of size of hundreds nm order with its lamellar space (d-spacing) of the order of $90 \mathrm{~nm}$ at the concentration from 1.5 to $80 \mathrm{mM}$. Goto et al. [23] have also reported from DSC measurement that the main endothermic peak appeared at $42{ }^{\circ} \mathrm{C}$ and corresponded to the $\mathrm{L}_{c}-\mathrm{L}_{\alpha}$ phase transition. The solution of [16-16] used in this study also might have shown the similar formation of VE, although sample preparation in this work is differed from that of the above references. This tendency is also maintained until $55{ }^{\circ} \mathrm{C}$, still maintaining of $1 / 2<\mathrm{CPP}<1$ condition. At $x_{[16-16]}=0.1$, the SM-ability of C16TAB is superior to VE-ability of [16-16] due to much more C16TAB than [16-16], consequently the formation of $\mathrm{SM}$ at $25{ }^{\circ} \mathrm{C}$. This tendency is maintained until $55^{\circ} \mathrm{C}$, still maintaining of $\mathrm{CPP}<1 / 3$ condition. At $0.2 \leq x_{[16-16]} \leq 0.4$, VE-forming ability of [16-16] is superior to $\mathrm{SM}$-forming ability of $\mathrm{C} 16 \mathrm{TAB}$, consequently the formation of $\mathrm{VE}$ at $25^{\circ} \mathrm{C}$. This means the change from CPP $<1 / 3\left(x_{[16-16]} \leq 0.1\right)$ to $1 / 2<\mathrm{CPP}<1$ conditions $\left(0.2 \leq x_{[16-16]} \leq 0.4\right)$. An increase in temperature $\left(35\right.$ and $\left.45^{\circ} \mathrm{C}\right)$ increases in the molecular motion of both C16TAB and [16-16]. This causes desorption of $\mathrm{Br}^{-}$atoms from the $\mathrm{VE}$ surface and charge repulsion between hydrophilic groups of two molecules. The alkyl chain interactions between two molecules, on the other hand, are maintained because of the same alkyl chain length. The increase in temperature, as a result, caused the decrease in $\mathrm{CPP}$ and promotion of the formation of WM. This also means the change from $1 / 2<\mathrm{CPP}<1$ to $1 / 3<$ $\mathrm{CPP}<1 / 2$ conditions. A further increase in temperature $\left(55^{\circ} \mathrm{C}\right)$ causes an increase in molecular motion and the structural transition of alkyl chain from trans- to gauche- structure [12], consequently the 
reformation of $\mathrm{VE}$. This also means the rechange from $1 / 3<\mathrm{CPP}<1 / 2$ to $1 / 2<\mathrm{CPP}<1$ conditions. At $x_{[16-16]} \geq 0.5$, both effects of stronger VE-forming ability of [16-16] than SM-ability of C16TAB and higher amount of [16-16] than that of C16TAB, has promoted the further formation of VE at $25^{\circ} \mathrm{C}$. This tendency is maintained until $55^{\circ} \mathrm{C}$, maintaining of $1 / 2<\mathrm{CPP}<1$ condition.

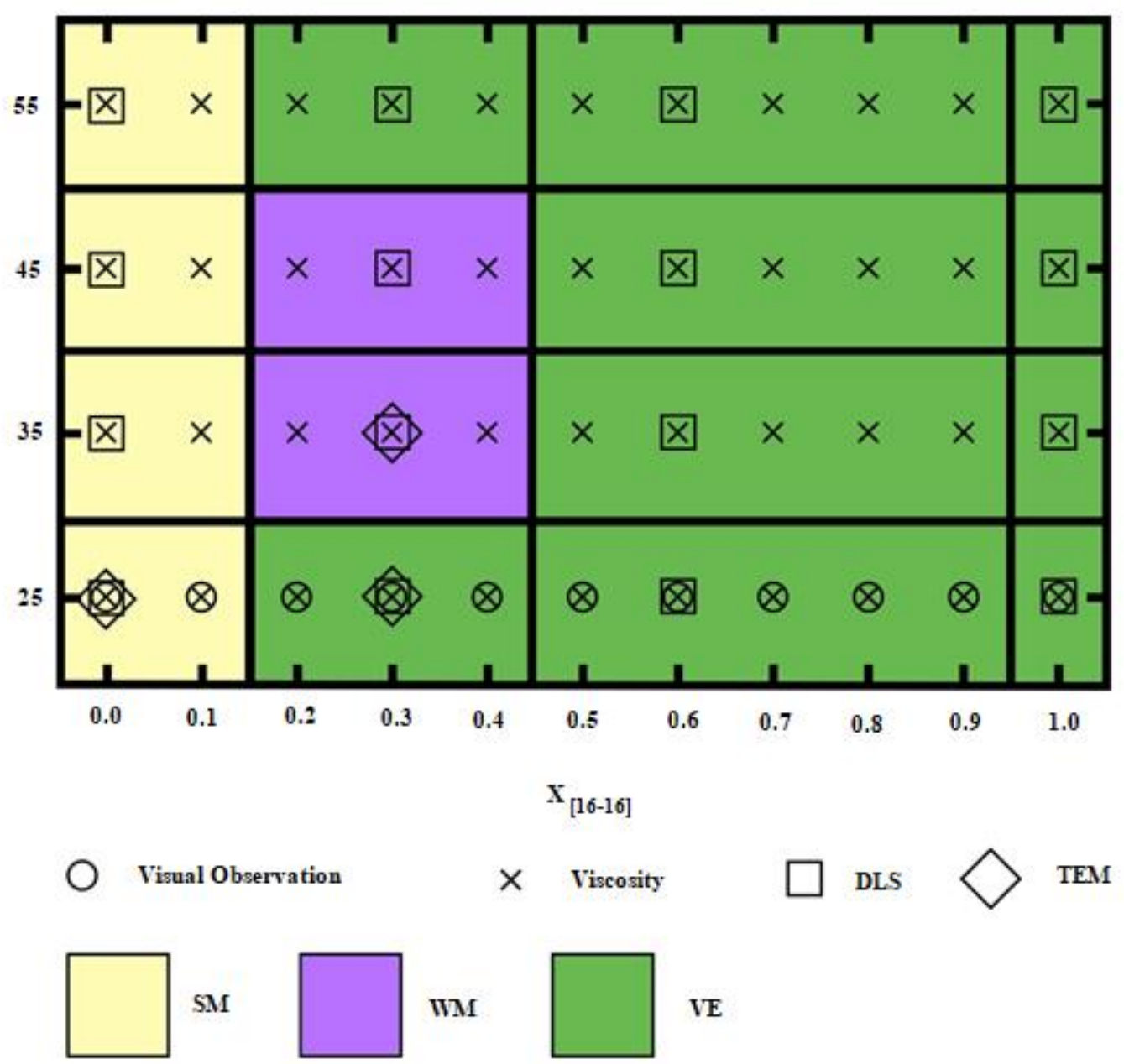

Fig. 5. Phase diagram of C16TAB-[16-16] mixed solutions. ○: Visual observation, $\times$ : Viscosity, $\square$ : DLS, $\diamond$ : TEM. Color: Light yellow (SM), Purple: WM, Green: VE.

\section{MATERIALS AND METHODS}

\section{A. Materials}

Ethanol $\left(\mathrm{C}_{2} \mathrm{H}_{5} \mathrm{OH},>99.5 \%\right)$, 1-propanol $\left(\mathrm{C}_{3} \mathrm{H}_{7} \mathrm{OH},>99.5 \%\right)$, 1-bromo hexadecane $\left(\mathrm{C}_{16} \mathrm{H}_{33} \mathrm{Br},>95.0 \%\right)$, acetone $\left(\mathrm{CH}_{3} \mathrm{COCH}_{3},>99.5 \%\right)$, and 1-hexadecyl trimethyl ammonium bromide $\left(\mathrm{C}_{16} \mathrm{H}_{33} \mathrm{~N}\left(\mathrm{CH}_{3}\right)_{3} \mathrm{Br}(\mathrm{C} 16 \mathrm{TAB}),>98.0 \%\right)$ were obtained from Wako Pure Chemical Industries Ltd., Osaka, Japan. N,N-dimethyl hexadecane amine were obtained from Tokyo Chemical Industry Co., Ltd., Tokyo, Japan. Compound of cationic dihexadecyl dimethyl ammonium bromide ([16-16]) was synthesized as follows. N,N-dimethyl hexadecane amine was treated with 1-bromo hexadecane in 1-propanol and refluxed at $100{ }^{\circ} \mathrm{C}$ in oil bath for 8 hours. After vacuum concentration and recrystallization by acetone (with) and ethanol, $\left(\mathrm{C}_{16} \mathrm{H}_{33}\right)_{2} \mathrm{~N}\left(\mathrm{CH}_{3}\right)_{2} \mathrm{Br}([16-16])$ was obtained. The product was identified by ${ }^{1} \mathrm{H}-\mathrm{NMR}$ and IR measurements.

\section{B. Sample Preparation}

Mixed surfactant solutions of C16TAB and [16-16] were prepared as follows; C16TAB and [16-16] for various mixing ratio $\left(x_{[16-16]}=0.0,0.1,0.2,0.3,0.4,0.5,0.6,0.7,0.8,0.9\right.$, and 1.0$)$ were dissolved in water. The concentration of each sample was $10 \mathrm{mmol} / \mathrm{kgfor}$ the investigation in the practical concentration range.Samplesolutions were sonicated, stirred, and heated at $60{ }^{\circ} \mathrm{C}$ to get homogeneous sample preparations. After the completion of the sample preparation, each solution was left at room temperature for one week before conducting the experiments. The measurements were conducted at temperatures $25,35,45$, and $55^{\circ} \mathrm{C}$. 


\section{Viscosity Measurement}

Viscosity measurements were conducted for various C16TAB-[16-16] mixed solutions using a rotary viscometer (TV-25, TOKI SANGYO CO., LTD.). Each $1.1 \mathrm{~mL}$ mixed sample solution was injected into a sample cup and measured at various rotational speeds (shear velocities: 1, 2, 5, 10, 20, 50, and $100 \mathrm{rpm}$; rotations per minute). The viscosity value recorded when rotational index became constant at each rotational speed.

\section{Dynamic Light Scattering (DLS) Measurement}

DLS measurements were performed for determining the size of aggregates formed in several C16TAB[16-16] mixed solutions using a DLS and Zeta Potential (ZP) measurement systems (Zetasizer Nano ZS, Malvern Panalytical Ltd.) with a $173^{\circ}$ backscattering detector and a He-Ne laser of $633 \mathrm{~nm}$. Each $1.0 \mathrm{~mL}$ mixed solution was injected into a sample cell through $0.20 \mu$ mmicroporous filter and measurement was done automatically. The number display on the particle size was estimated through the following transmission electron microscope (TEM) observation. Zeta potential of the solution (aggregates) was also measured at the same time. As apparent spherical aggregates for this research, the mean diffusion coefficient $(D)$ is converted to the apparent hydrodynamic diameter $\left(d_{\mathrm{H}}\right)$ using the Sotkes-Einstein equation,

$$
d_{\mathrm{H}}=k T / 3 \pi \eta D
$$

where $k$ is the Boltzmann constant, $T$ is the absolute temperature, $\eta$ is solvent viscosity.

\section{E. Transmission Electron Microscope (TEM) Observation}

TEM observations were recorded for the microstructures of aggregates in two C16TAB-[16-16] mixed solutions $\left(x_{[16-16]}=0.0,0.3\right)$ using a TEM microscope systems (JEM-1400Plus, JEOL Ltd.). Samples were prepared by negative staining method as follows. The hydrophilic treated copper mesh (ELS-C10, STEM Co. Ltd.) was placed on the droplet of mixed solution at each temperature $\left(25\right.$ and $\left.35{ }^{\circ} \mathrm{C}\right)$, and subsequently the droplet of staining solution (phosphotungstic acid hydrate solution (KATAYAMA CHEMICAL INDUSTRIES CO. LTD., Spc. Gra.)) was loaded on the mesh. The substrate, after drying of samples and removing of excess solution by filter paper, was used as TEM sample.

\section{CONCLUSION}

In this study, we have investigated the $x_{[16-16]}$ and temperature effects of [16-16] to C16TAB in the practical concentration range $(10 \mathrm{mmol} / \mathrm{kg}$ fixed) using various physicochemical methods. The transition from SM to VE was observed with an increase in the mixing ratio. WM was also formed in the solution at the specific ratio $\left(0.2 \leq x_{[16-16]} \leq 0.4\right)$ and temperature $\left(35\right.$ and $\left.45^{\circ} \mathrm{C}\right)$. This study provides the fact that even a simple surfactant like $\mathrm{C} 16 \mathrm{TAB}$ and [16-16] used in this study can control various aggregate formations such as not only SM and VE but also WM, depending on the simple condition like $x_{[16-16]}$ and temperature change and the coexistence effect between aggregates. Further study may also help to understand the structural characteristics on the intermolecular interaction in two cationic mixed surfactants and connect to various possibilities and applications such as not only the above-mentioned dispersion, emulsification, and solubilization but also oil gelling agents, artificial cells, and development of biocompatible materials using surfactants.

\section{REFERENCES}

[1] Kawai T. Interfaces and Surfactants: Fundamentals and Applications. Japan Oil Chemists'Society, Tokyo; 2020.

[2] Abe M, Horiuchi T. Functional Creation • Material Development • Applied Technology of Surfactants. Revised Edition, Gizyutukyouiku Ltd. Tokyo; 2011.

[3] Israelachvili JN. Intermolecular and Surface Forces. Third Edition; Asakura Pub. Co., Ltd.; 2013.

[4] Rigaud J, Pitard B, Levy D. Reconstitution of membrane proteins into liposormes: application to energy-transducing membrane proteins. Biochimica et Biophysica Acta. 1995;1231:223-246.

[5] Kashiwagi H, Ueno M. Mechanism of Micelle-Vesicle Transformation and Control of Vesicular Sizes and Properties. YAKUGAKU ZASSHI. 2008;128:669-680.

[6] Lichtenberg D. Characterization of the solubilization of lipid bilayers by surfactants. Biochimica et Biophysica Acta. 1985;821:470-478.

[7] Tian M, Fan Y, Ji G, Wang Y. Spontaneous Aggregate Transition in Mixtures of a Cationic Gemini Surfactant with a Double-Chain Cationic Surfactant, Langmuir. 2012;28:12005-12014.

[8] Kushimoto S, Yamanouchi S, Endo T, Sato T, Nomura R, Fujita M, Kudo D, Omura T, Miyagawa N, Sato T, Body temperature abnormalities in non-neurological critically ill patients: A review of the literature. Journal of Intensive Care. 2014;2:14-19.

[9] Zhou K, Wang Y, Huang X, Katherine K. Luby-Phelps, Sumer Baran D., Gao J. Tunable, Ultra-Sensitive pH Responsive Nanoparticles Targeting Specific Endocytic Organelles in Living Cells. Angewandte Chemie International Edition in English. 2011;50:6109-6114. 
[10] Oyama N. Colloid and Surface Chemistry. 4th Ed., Maruzen Publishing Co., Ltd., Tokyo, 2018.

[11] Koehler RD, Raghavan SR, Kaler EW. Microstructure and Dynamics of Wormlike Micellar Solutions Formed by Mixing Cationic and Anionic Surfactants. Journal of Physical Chemistry B.2000;104:11035-11044.

[12] Khatory A, Kern F, Lequeux F, Appell J, Porte G, Morie N, Ott A, Urbach W. Entangled versus Multiconnected Network of Wormlike Micelles. Langmuir. 1993;9:933-939.

[13] Application of Dynamic Light Scattering (DLS) to Protein Therapeutic Formulation: Principles, Meausrements and Analysis3.DLS Deconvolution Algorithms. [Internet] [updated February 7, 2014]. https://www.malvernpanalytical.com/en/learn/knowledge-center/whitepapers/WP140207ApplicDLSprotein3.

[14] Bharmoria P, Vaneet, Banipal PK, Kumar A, Kang TS. Modulation of Micellization Behavior of Cetyltrimethylammonium Bromide (CTAB) by Organic Anions in Low Concentration Regime. Journal of Solution Chemistry.2015;44:16-33.

[15] Silva JA, Dias RP, Hora GCA, Soares TA, Meneghetti MR. Molecular Dynamics Simulations of Cetyltrimethylammonium Bromide (CTAB) Micelles and their Interactions with a Gold Surface in Aqueous Solution, Journal of the Brazilian Chemical Society.2018;29:191-199.

[16] Tanford C. The Hydrophobic Effect: Formation of Micelles and Biological Membranes, Krieger Publishing Co., Florida. 1991.

[17] Liberatore MW, Nettesheim F, Vasquez PA, Helgeson ME, Wagner NJ, Kaler EW, Cook LP, Porcar L, Hu YT. Microstructure and shear rheology of entangled wormlike micelles in solution, Journal of Rheology.2009;53:441-458.

[18] Kwlatkowski AL, Molchanov VS, Phillippova OE. Polymer-like Wormlike Micelles of Ionic Surfactants: Structure and Rheological Properties, Polymer Science, Series A, 2019;61:215-225.

[19] Zou W, Tan G, Jiang H, Vogtt K, Weaver M, Koenig P, Beaucageb G, Larson RG, From well-entangled to partially-entangled wormlike micelles. Soft Matter. 2019;15:642-655.

[20] Rosen MJ, Kunjappu JT. Surfactants and Interfacial Phenomena 4th Ed., John Wiley \& Sons, New York, 2012.

[21] Ghimire Y, Amatya S, Shah SK, Bhattarai A. Thermodynamic properties and contact angles of CTAB and SDS in acetonewater mixtures at different temperatures, SN Applied Sciences. 2020;2:1295.

[22] Tucker I, Penfold J, Thomas RK, Grillo I, Barker JG, Mildner DFR. The Surface and Solution Properties of Dihexadecyl Dimethylammonium Bromide. Langmuir. 2008;24:6509-6520.

[23] Goto M, Ishida S, Ito Y, Tamai N, Matsuki H, Kaneshina S, Thermotropic and Barotropic Phase Transitions of Dialkyldimethylammonium Bromide Bilayer Membranes: Effect of Chain Length. Langmuir. 2011;27:5824-5831. 